\title{
Retinoic Acid Modulates Rat Ito Cell Proliferation, Collagen, and Transforming Growth Factor $\beta$ Production
}

\author{
Bemard H. Davis, Robyn T. Kramer, and Nicholas O. Davidson \\ Gastroenterology Section, Department of Medicine, University of Chicago, Chicago, Illinois 60637
}

\begin{abstract}
Recent studies suggest that vitamin A plays an inhibitory role with respect to "activation" of the hepatic Ito cell, a likely effector of hepatic fibrogenesis. Ito cell "activation" during fibrogenesis is characterized by a decrease in intracellular vitamin $A$ and an increase in cellular proliferation and collagen production. To explore the hypothesis that retinoids have the capacity to diminish Ito cell activation, cultured Ito cells were exposed to retinoic acid and its effects assessed on three key features: cell proliferation, collagen protein production and mRNA abundance, and transforming growth factor $\beta$ protein production. Retinoic acid was 100-1,000 $\times$ more potent than retinol with respect to inhibition of Ito cell proliferation. Interstitial collagen and transforming growth factor $\beta$ production were also reduced by $10^{-6} \mathrm{M}$ retinoic acid. The relative abundance of type I collagen mRNA however, was not significantly altered. By contrast, retinoic acid administration to rats caused a marked reduction in the abundance of type I collagen mRNA in both total hepatic and purified Ito cell RNA. The relative abundance of rat hepatic fibronectin or apolipoprotein $E$ mRNA was not significantly altered. These studies demonstrate that retinoic acid can differentially modulate several key features of hepatic fibrogenesis in vitro and in vivo. (J. Clin. Invest. 1990. 86:2062-2070.) Key words: hepatic fibrosis • vitamin $\mathbf{A} \cdot$ cirrhosis $\bullet$ nodule formation $\bullet$ cytokines
\end{abstract}

\section{Introduction}

The factors that potentially modulate hepatic collagen overproduction and cellular proliferation in vivo, the key features of hepatic cirrhosis, are poorly understood. Recent molecular studies of models of hepatic regeneration or fibrosis suggest that a variety of cytokines including transforming growth factors $(\mathrm{TGF})^{1}$ alpha and beta may play a key role in some of

Portions of this work were presented at the May 1989 American Federation of Clinical Research meeting in Washington DC and at the October 1989 American Association for the Study of Liver Disease meeting in Chicago IL, and were published in abstract form in Clin. Res. 37:367a. (Abstr.) and Hepatology. 10:630.

Address reprint requests to Dr. Bernard H. Davis, Gastroenterology Section, Department of Medicine, University of Chicago Medical Center, Box 400, 5841 South Maryland Avenue, Chicago, IL 60637.

Received for publication 4 December 1989 and in revised form 24 July 1990.

1. Abbreviations used in this paper: BAPN, beta-aminoproprionitrile; TGF, transforming growth factor.

J. Clin. Invest.

(C) The American Society for Clinical Investigation, Inc. 0021-9738/90/12/2062/09\$2.00

Volume 86, December 1990, 2062-2070 these processes (1-3). While the cellular source(s) of these regulatory cytokines are unknown, several studies suggest that mesenchymal cells in general have the capacity to produce these factors $(4,5)$. In the liver, several laboratories have found that the non-parenchymal sinusoidal Ito cell (or lipocyte, fatstoring or stellate cell) has the capacity to produce the majority of the extracellular matrix proteins that accumulate during fibrosis and cirrhosis as well as significant amounts of TGF $\beta$ mRNA (6-10). During fibrosis, the Ito cell loses its abundant vitamin A stores and appears to proliferate and transform into a synthetically active cell resembling a myofibroblast (11-14). Recent in vitro evidence indirectly suggests that this loss of vitamin A may play a causal role in the cellular transformation since (1) a Kupffer cell-derived "activating" factor promotes the loss of the intracellular vitamin $A$ and an increase in collagen production, (2) the passive loss of the intracellular vitamin $A$ in early tissue culture occurs coincident with the morphologic transformation and cellular proliferation, and (3) reexposure of the cells to retinol, the physiologic form of vitamin A metabolized by Ito cells in vivo, results in intracellular retinol uptake with the formation of predominantly retinol palmitate (as in vivo) and the concomitant depression of cell proliferation and collagen production (15-21). In addition, exposure of Ito cells to the aforementioned TGF $\beta$ cytokine upregulates the amount of interstitial collagen produced as well as depressing the cell's ability to store vitamin A $(19,21)$. These observations generally suggest that "activated" Ito cells in vivo or in vitro may undergo large shifts in the relative amount of intracellular vitamin A. It is currently unclear whether the physiologic effector molecule is actually retinol or the more potent retinoic acid. Work in other cell systems suggests furthermore that absolute measurements of intracellular retinol or retinoic acid may be less critical than the subtle balance between the relative amount of cytoplasmic and nuclear retinoids that are being shuttled between the two cell compartments by highly specific binding proteins (22-27). While the above work demonstrated that retinol can modulate Ito cell behavior, the possible direct contribution of retinoic acid is unknown. The Ito cell has been shown to contain the cytoplasmic binding proteins for both retinol and retinoic acid which suggests its normal capacity to metabolize or respond to both forms of the vitamin $(22,23)$. Retinoic acid has been shown to modulate differentiation in a wide variety of cell types, an effect whose mechanism(s) may involve interaction with distinct, specific forms of nuclear receptors (24-27). Accumulated evidence suggests that retinoic acid is internalized by the cell, transported to the nucleus bound specifically to cellular retinoic acid binding protein, and then interactions occur with a variety of nuclear retinoic acid binding proteins with shared structural features, suggesting their capacity to function as DNA binding proteins (25-27).

This study examined the effects of retinoic acid upon the modulation of hepatic and Ito cell gene expression in vivo and in vitro. The goal was to determine whether exposure to reti- 
noic acid could effectively alter some of the key events associated with hepatic fibrogenesis. Since retinoic acid has generally been found to be more potent than retinol, this retinoid was studied as a potential probe that could then be used to dissect the regulatory factors involved in these central pathogenic processes. It was found that the proliferation of cultured Ito cells together with collagen and TGF $\beta$ production can be significantly inhibited by the addition of retinoic acid in vitro. Modulation of collagen production, however, after in vivo administration of retinoic acid, was associated with a decrease in type I collagen mRNA abundance, whereas in cultured Ito cells, retinoic acid administration does not appear to change the relative abundance of the collagen mRNA. This study suggests that retinoic acid has the capacity of altering collagen production by different mechanisms in vivo and in vitro.

\section{Methods}

Animals. Sprague-Dawley male rats ( $>500 \mathrm{~g}$ ) were routinely used for cell isolation or in vivo retinoic acid administration (Harlan Inc., Indianapolis, IN). For in vivo administration of retinoic acid, C57BL/6J mice (The Jackson Laboratory, Bar Harbor, ME) were also used.

Chemicals. Retinoic acid or 13-cis retinoic acid (Sigma Chemical Co., St. Louis, MO) used in the cell culture experiments were prepared as stock $10^{-3} \mathrm{M}$ solutions in $100 \%$ ethanol and stored under nitrogen in brown bottles at $-20^{\circ} \mathrm{C}$ for $<1 \mathrm{wk}$. When retinoic acid was used for in vivo intraperitoneal injections $(1 \mu \mathrm{g} / \mathrm{g}$ ), it was prepared from a freshly opened vial by sonication in olive oil. All work with retinoic acid was performed under reduced lighting conditions.

Cell isolation/cell culture. Hepatic Ito cells were isolated as previously described in detail (8). The only modification was that the use of older and larger rats eliminated the need for pretreatment of the animals with retinol acetate. When the cells were used for RNA extraction after fresh isolation, the use of pronase was avoided to minimize the degree of contaminating cellular debris. The cells were routinely cultured and subcultured (one to two passages) on tissue culture flasks precoated with calf type I collagen as previously described (8).

Collagen quantitation. Using previously described ELISAs for rat type I and type III collagen, the amount of accumulated collagen was separately quantitated for the cell culture media and the cell layer collagen (8). The collagen quantitation experiments were performed in tissue culture media containing $10 \%$ fetal calf serum supplemented with ascorbic acid $(50 \mu \mathrm{g} / \mathrm{ml})$ and beta-aminoproprionitrile (BAPN) $(100 \mu \mathrm{g} / \mathrm{ml})$. Confluent monolayers of cells (in groups of 4 parallel wells in 24-well plates) were incubated in this media for an initial $48 \mathrm{~h}$ supplemented twice daily with ascorbic acid and BAPN. The media contained retinoic acid (final concentration: $10^{-6}-10^{-8} \mathrm{M}$ ) or an equivalent amount of ethanol $(0.1 \%)$. Preliminary studies suggested that this amount of ethanol had no effect on baseline collagen quantitation or cell proliferation (data not shown). Addition of retinoic acid was performed under reduced lighting conditions. This dose of retinoic acid did not cause any loss of cell number or any alteration in cell morphology as assessed by phase contrast or Hoffman optic microscopy (Olympic Corp., Woodbury, NY). After this initial incubation, the media was changed and the amount of collagen in a final 48-h incubation was quantitated in duplicate and expressed per well of cells. In contrast to earlier studies in which shorter incubation periods were used, the current protocol includes a final 48-h period of collagen accumulation which has consistently yielded a collagen type I/type III ratio $=3.8 \pm 1.7$ ( $n=35$ cultures) $(8,19)$. Type IV collagen has consistently contributed $<10 \%$ of total collagen (data not shown). The experiments were performed in serum-containing media, as preliminary studies demonstrated that cell viability is rapidly lost in serum-free media during prolonged incubations (data not shown), and prior work involving retinol metabolism demonstrated that these tissue culture conditions permitted retinol uptake and retinol esterification, which are characteristics of the in vivo response (21). The absolute amount of DNA/well varied between experiments in the range of $0.5-1.0 \mu \mathrm{g}$ DNA/well, but with no significant trend within any one experimental group.

Cell proliferation. Ito cells (groups of 2-4 parallel wells) were cultured on 24 -well plates precoated under sparse conditions $(\approx 50 \%$ confluent) in media containing $10 \%$ fetal calf serum \pm retinoic acid (or the equivalent amount of ethanol [0.1\%] diluent) for $24-48 \mathrm{~h} .\left[{ }^{3} \mathrm{H}\right]-$ Thymidine incorporation was then determined via the method of McGowan et al. (28). Preliminary work suggested that the use of sparse cultures maximized $\left[{ }^{3} \mathrm{H}\right]$ thymidine incorporation versus confluent cultures. Control groups included cells exposed to $0.4 \%$ fetal calf serum that reduced $\left[{ }^{3} \mathrm{H}\right]$ thymidine incorporation to a baseline level typical of mesenchymal cells. In addition, cells were exposed to $10 \%$ fetal calf serum in the presence of hydroxyurea to determine the contribution of DNA repair to apparent DNA synthesis (28).

$R N A$ quantitation. The in vitro effects of retinoic acid on Ito cell type I collagen mRNA abundance were assessed by exposing confluent monolayers (2-4 75- $\mathrm{cm}^{2}$ flasks/condition, precoated with calf type I collagen as stated above) of cells to retinoic acid $\left(10^{-6} \mathrm{M}\right)$ for $48 \mathrm{~h}$. The tissue culture media contained ascorbic acid $(50 \mu \mathrm{g} / \mathrm{ml})$ to promote collagen secretion and had either 10 or $0.4 \%$ fetal calf serum. RNA extraction was performed directly into $4 \mathrm{M}$ guanidinium thiocyanate as described below. To assess the potential in vivo alterations in the relative abundance of type I collagen, fibronectin and apolipoprotein $E$ transcripts, animals were given intraperitoneal doses of retinoic acid (1 $\mu \mathrm{g} / \mathrm{g}) 72$ and $24 \mathrm{~h}$ before being killed. Control animals were given an equivalent amount $(0.5 \mathrm{ml} / \mathrm{animal})$ of olive oil. This dose and administration frequency were based on a previously determined rate of Ito cell vitamin $A$ accumulation, after in vivo administration, with the intention of maximizing the amount of intracellular vitamin $A$ in the liver (unpublished observations) $(22,23)$. In addition, this dose of vitamin $A$ did not induce any changes in animal weight or liver histology and it approximated the dose used therapeutically in dermatologic disorders (29-31).

Animals were killed after terminal exsanguination and portions of the liver were snap frozen in liquid nitrogen and stored at $-70^{\circ} \mathrm{C}$ for later RNA extraction. For quantitation of fresh Ito cell mRNA, rats were prepared for portal vein perfusion as stated above. Immediately after the initiation of perfusion with PBS, a portion of the right hepatic lobe was isolated, excised, and snap frozen as above. The remaining liver was perfused, the Ito cells purified, and the cell pellet used immediately for RNA extraction. RNA extraction was performed by homogenization in $4 \mathrm{M}$ guanidinium thiocyanate followed by phenolchloroform extraction (32). The RNA was quantitated spectrophotometrically and was then analyzed by formaldehyde/agarose electrophoresis and transblotted to nylon (Zeta-probe; Bio-Rad Laboratories, Richmond, CA) membranes. Ethidium bromide staining was used to assess the relative amount and the intact nature of the RNA. Northern blots containing whole liver RNA were loaded with $25 \mu \mathrm{g} /$ lane while those with either cultured or fresh Ito cell RNA contained 2 or $5 \mu \mathrm{g}$, respectively. Subsequent probing of the Northern blot hybridizations was performed using cDNAs labeled to a specific activity of $1-2 \times 10^{9}$ $\mathrm{cpm} / \mu \mathrm{g}$ by random priming (33). The cDNAs used include a $\beta$-actin, apolipoprotein $\mathrm{E}$, fibronectin, and an $18 \mathrm{~s}$ ribosomal probe as well as a rat alpha ${ }_{1}(1)$ collagen probe (34-38). Nylon filters were prehybridized and hybridized at $42^{\circ} \mathrm{C}$ in $50 \%$ formamide containing $6 \times$ SSC, $50 \mathrm{mM}$ Na phosphate pH7, $1 \mathrm{mM}$ EDTA, $1 \times$ Denhardts solution, $50 \mu \mathrm{g} / \mathrm{ml}$ sheared single-stranded salmon sperm DNA, and $10 \%$ dextran sulfate. Prehybridization was for $4 \mathrm{~h}$ and hybridization was for $24 \mathrm{~h}$ in the presence of $1 \times 10^{6} \mathrm{cpm} / \mathrm{ml} \mathrm{cDNA}$. Washing stringencies for these cDNAs included four room temperature incubations with $0.1 \%$ SDS $/ 1 \times$ SSC and two washes at $50^{\circ} \mathrm{C}$ in $0.1 \times$ SSC. Autoradiograms were developed using Kodak XAR- 5 film and intensifying screens at $-80^{\circ} \mathrm{C}$. For Northern blots comparing whole liver RNA, the relative signal intensities were compared with the abundance of an $18 \mathrm{~s}$ ribosomal probe. 
TGF $\beta$ quantitation. To estimate the relative amount of the TGF $\beta$ protein produced by Ito cells in culture, the cells were grown to confluence in 24-well plates precoated with calf type I collagen as stated above. The cultures were then maintained in media containing $0.4 \%$ fetal calf serum \pm retinoic acid $\left(10^{-6} \mathrm{M}\right.$ or the equivalent amount of ethanol diluent) for $48 \mathrm{~h}$. Studies were done in media containing reduced serum to minimize the potential modulation by other mediators present in serum as well as to limit the relative amount of alpha-2-macroglobulin that might bind the TGF $\beta(40)$. Media was aliquoted and stored at $-70^{\circ} \mathrm{C}$ and defrosted just before quantitation. The relative amount of secreted TGF $\beta$ was adjusted for the amount of DNA/well.

TGF $\beta$ was quantitated via ELISA. The TGF $\beta_{1}$ protein and a rabbit polyclonal anti-TGF $\beta$ antiserum used in the development of an ELISA were kindly provided by Dr. Roberts and Dr. Danielpour National Institutes of Health $(4,5)$. It was stored, lyophilized at $-70^{\circ} \mathrm{C}$, and was reconstituted and kept at $4^{\circ} \mathrm{C}$ for 2-3 wk only. The antiserum was used in an ELISA at a 1:500 dilution using PBS containing 0.06\% Triton$\mathrm{X}-100$ and $0.05 \% \mathrm{BSA}$ as diluent. The TGF $\beta$ used was stored as a stock concentration of either 20 or $2,000 \mathrm{ng} / \mathrm{ml}$ in $4 \mathrm{mM} \mathrm{HCl} / 0.1 \%$ BSA at $-70^{\circ} \mathrm{C}$ and was defrosted before use and kept at $4^{\circ} \mathrm{C}$ for $<1$ wk.

To quantitate the TGF $\beta, 96$-well microtiter plates were coated with varying amounts of TGF $\beta$ in duplicate wells $(100 \mu \mathrm{l} /$ well). The TGF $\beta$ was serially diluted with a bicarbonate buffer $\left(0.015 \mathrm{M} \mathrm{Na}_{2} \mathrm{CO}_{3} / 0.03\right.$ $\mathrm{M} \mathrm{NaHCO}$ ) and neutralized in the microtiter wells with an appropriate amount of $40 \mathrm{mM} \mathrm{NaOH}$. Control wells included an equal amount of $0.1 \%$ BSA. The samples were similarly diluted in the bicarbonate buffer and 3-4 dilutions were made for each sample (starting dilutions at 1:5 or 1:10). The plates were wrapped in Saran wrap and kept at $4^{\circ} \mathrm{C}$ for $1-3 \mathrm{~d}$ before use (similar results were obtained if the plates were coated, incubated at $37^{\circ} \mathrm{C}$ for $4 \mathrm{~h}$, and then assayed directly). Preliminary work suggested that preincubating the diluted antiserum in microtiter wells coated with TGF $\beta$ at $2 \mathrm{ng} /$ well completely eliminated the anti-TGF $\beta$ activity. The coated plates were initially washed 3 times in PBS with $0.06 \%$ Triton and then incubated with the diluted anti-TGF $\beta$ serum for $2 \mathrm{~h}$ at room temperature. This was followed by 3 additional washes with all subsequent steps similar to previously published collagen ELISA techniques (8). The final colorcontaining agent was incubated for $2-4 \mathrm{~h}$ in the dark at room temperature. The absorbance detection at $492 \mathrm{~nm}$ was performed using a Bio-Rad Laboratories ELISA reader interfaced with the Macreader program and a Mac-Plus computer. The absorbance slopes from loglinear graphing were calculated using linear regression generated lines from the Macreader or Cricket Graph programs. The slopes obtained for the standard TGF $\beta$ curve and the cell media samples were parallel within $10-20 \%$ (Fig. 1).

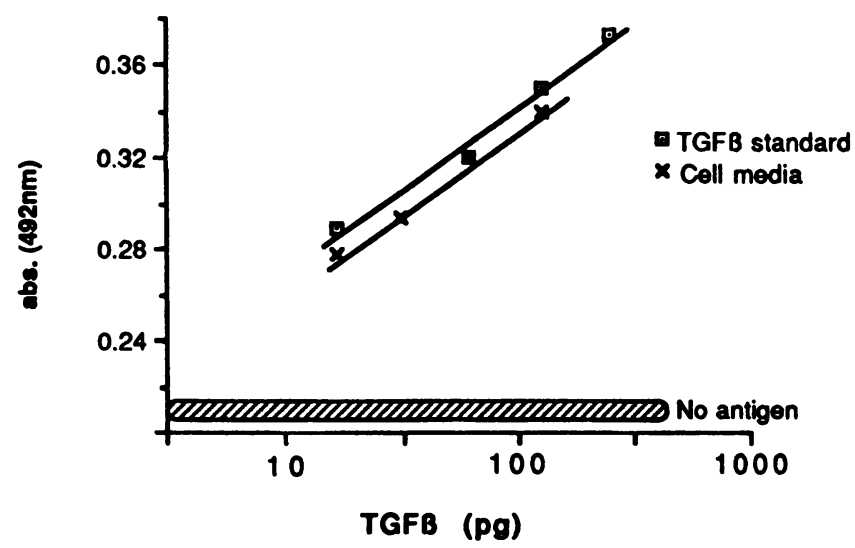

Figure 1. TGF $\beta$ ELISA. Representative ELISA of TGF $\beta$ (with BSAcontaining diluent) and serial dilution of Ito cell media. The initial dilution of cell media was 1:5. Linear regression-generated slopes are parallel. The background absorption to BSA-coated ( $1 \mu \mathrm{g} / \mathrm{well})$ wells is shown as "No antigen."

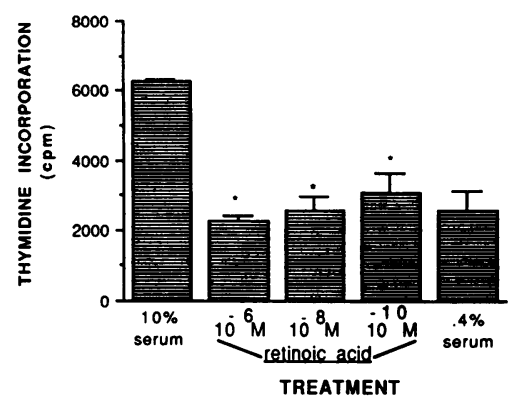

Figure 2. Retinoic acid modulation of Ito cell proliferation. Subconfluent cultures of early passage Ito cells maintained on type I collagen coated wells in media containing $10 \%$ fetal calf serum were exposed to varying concentrations of retinoic acid for $48 \mathrm{~h}$ and the

degree of $\left[{ }^{3} \mathrm{H}\right]$ thymidine incorporation was subsequently determined. The degree of thymidine incorporation was contrasted to cells made quiescent by culturing with $0.4 \%$ fetal calf serum for the $48 \mathrm{~h}$ ( $n$ $=4) .{ }^{*} P<0.001$ (vs. $10 \%$ serum).

Statistical analysis. Unpaired Student's $t$ test was used to evaluate differences between various subgroups.

\section{Results}

Modulation of Ito cell proliferation. As shown in Figs. 2 and 3, retinoic acid caused a marked inhibition of Ito cell growth as assessed by $\left[{ }^{3} \mathrm{H}\right]$ thymidine incorporation. Preliminary work with retinoic acid (data not shown) demonstrated that it additionally prevented an increase in cell number, an effect similar to that previously observed with retinol (20). In contrast to retinol, however, which had a submaximal effect at a $10^{-6} \mathrm{M}$ concentration and no effect at a $10^{-7} \mathrm{M}$ concentration, retinoic acid still had a significant inhibitory effect at a $10^{-10} \mathrm{M}$ concentration (20). Recent estimates of circulating retinoic acid levels in human serum suggest that culture media containing $10 \%$ fetal calf serum may have $\leq 10^{-10} \mathrm{M}$ retinoic acid (38). However, due to retinoic acid's relative instability, we speculate that the effective retinoic acid concentration in cul-

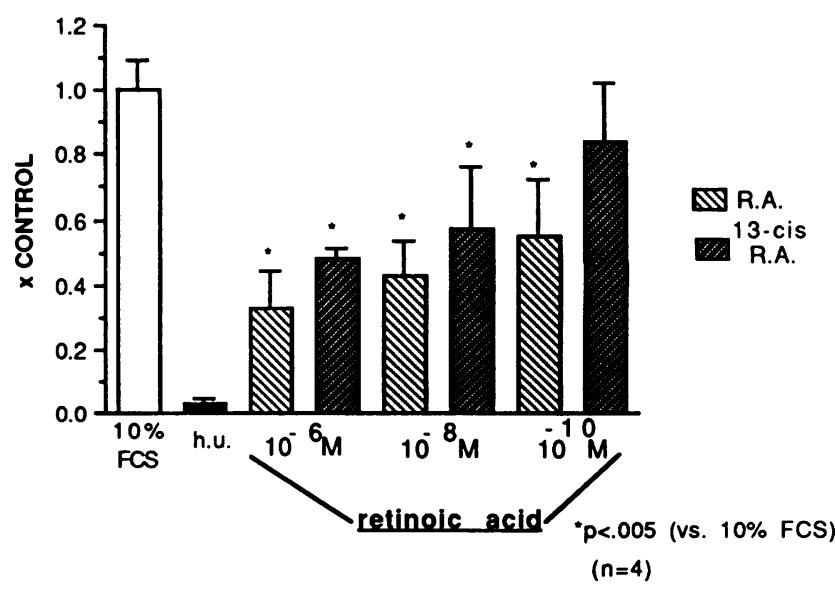

Figure 3. Modulation of Ito cell proliferation: trans-retinoic acid vs. 13-cis-retinoic acid. Cells were treated as described in Fig. 2, except for additional cells exposed to parallel levels of 13-cis-retinoic acid. Due to different degrees of absolute stimulation between separate experiments, the data is expressed as a percentage of the control cells maintained in $10 \%$ fetal calf serum. To estimate the contribution of DNA repair (versus DNA synthesis) to $\left[{ }^{3} \mathrm{H}\right]$ thymidine incorporation, some wells were exposed to $10 \%$ fetal calf serum $(F C S)+$ hydroxyurea (h.u.). 
ture media may be considerably lower (24). Using previously described HPLC methodology with a $25 \mathrm{ng}$ limit of detection, retinoic acid was undetectable in the fetal calf serum used in these experiments ( $<25 \mathrm{ng} / 500 \mu$ l whole serum), corresponding to a maximum concentration of $10^{-8} \mathrm{M}$ in $10 \%$ fetal calf serum and $4 \times 10^{-10} \mathrm{M}$ in $0.4 \%$ fetal calf serum (20).

The marked difference in the potency of retinol versus retinoic acid has been previously noted and parallels the observed differences in their serum concentrations (retinol $10^{-6}$ $M$ versus retinoic acid $<10^{-9} \mathrm{M}$ ) as well as the intracellular Ito cell concentrations of the respective cytosolic binding proteins $(22,24,42)$. The medically used and related 13-cis-retinoic acid caused similar inhibition of cell proliferation at the $10^{-6}-10^{-8} \mathrm{M}$ range. Thus, while some work has indicated that the intracellular metabolism of 13-cis isomer may differ from the all-trans isomer, it appears that Ito cell proliferation responds similarly to both compounds (43).

In vitro modulation of collagen production. As shown in Fig. 4, retinoic acid treatment caused a marked decrease in the amount of total and secreted type I and type III collagen over a 48-h period. As noted previously, in this "activated" Ito cell culture system, the amount of type I collagen exceeds the amount of type III collagen and the majority of the collagen is secreted directly into the culture media (19). Fig. 5 demonstrates a concentration-dependent effect of retinoic acid upon collagen secretion with a significant level of inhibition demonstrable at a $10^{-8} \mathrm{M}$ retinoic acid concentration. Steady-state levels of the type I collagen transcript were not altered in RNA extracted from confluent monolayers of Ito cells cultured in the presence of $10^{-6} \mathrm{M}$ retinoic acid (24-48 h) using media containing either 10 or $0.4 \%$ fetal calf serum (Fig. 6). Equivalence of RNA transfer was independently confirmed by reprobing the same Northern blot with an $18 \mathrm{~s}$ ribosomal probe. This suggests that in vitro retinoic acid may alter collagen production at a translational or posttranslational level.

In vitro modulation of TGF $\beta$ production. TGF $\beta$ mRNA abundance has been shown to be elevated in vivo during hepatic fibrogenesis and during certain phases of hepatic regeneration (1-3). While the passaged Ito cell retains its native ability to esterify and hydrolyze vitamin $A$, it best reflects the

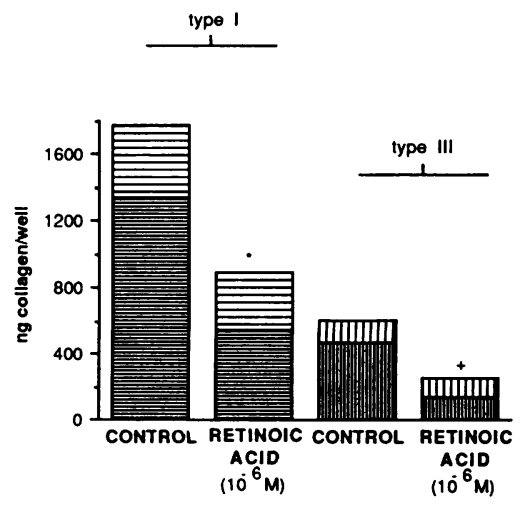

Figure 4. Retinoic acid modulation of Ito cell type I and type III collagen production. Confluent cell cultures exposed to $10^{-6} M$ retinoic acid were assayed for the amount of secreted and cell-associated type I and III collagen by ELISA. As previously reported, the majority of the interstitial collagen is secreted (8). The amount of total (secreted + cell layer) or secreted collagen was significantly reduced by retinoic acid. All wells had comparable amounts of DNA. 目 Type I collagen, secreted; $\square$ type I collagen, cell layer; $\square$ type III collagen, secreted; $\square$ type III collagen, cell layer. *Secreted: $P<.009$ vs. CONTROL, cell layer: NS; ${ }^{+}$secreted: $P<.001$ vs. CONTROL, cell layer: NS $(n=4)$.

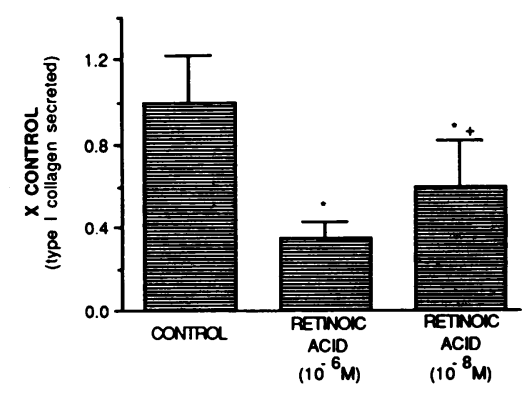

Figure 5. Type I collagen secretion versus retinoic acid concentration. The effect of two retinoic acid concentrations were examined with respect to type I collagen secretion, as described in Fig. 4. Due to different degrees of absolute collagen production between differ-

ent experiments, the data is expressed as a percentage of the control wells exposed to $10 \%$ FCS. ${ }^{*} P<0.01$ vs. Control; ${ }^{+} P<0.05$ vs. Retinoic acid $\left(10^{-6} \mathrm{M}\right)(n=4-8)$.

fibrogenic "activated" Ito cell with dilated rough endoplasmic reticulum, prominent microfilaments, the production of predominantly interstitial collagen type $I$, and active proliferation $(8,17)$. It was found that these Ito cells produced $31 \pm 15 \mathrm{pg} /$ well $(n=4)$ TGF $\beta$ when cultured under "quiescent" conditions with $0.4 \%$ fetal calf serum. This is comparable to levels previously reported for macrophages (44). The ability to produce significant quantities of this cytokine represents an additional key feature that makes the in vitro Ito cell a likely mirror of many of the features of an in vivo hepatic fibrogenic effector cell. Ito cells exposed to $10^{-6} \mathrm{M}$ retinoic acid for $48 \mathrm{~h}$ in the presence of $0.4 \%$ fetal calf serum had undetectable levels of TGF $\beta$ (10 pg detection limit) $(n=4)$. It is possible that the normal (nonactivated) in vivo Ito cell with its relatively high intracellular retinoid concentration may have its endogenous capacity to produce TGF $\beta$ suppressed.

In vivo modulation of collagen production. To parallel some of these studies in vivo, rats and mice were exposed to retinoic acid in concentrations that approximated the doses used clinically for dermatologic disorders (29-31). The relative

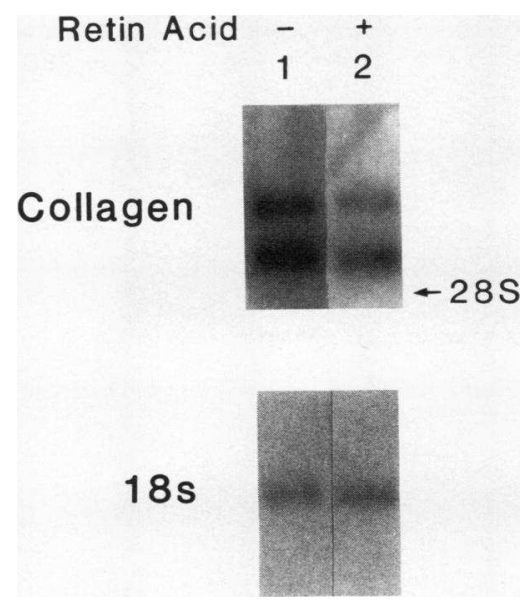

Figure 6. Retinoic acid modulation of alpha 1 (1) collagen mRNA abundance in vitro. Confluent cultures of Ito cells maintained on type I collagen-coated flasks in $0.4 \%$ FCS were exposed to $10^{-6} \mathrm{M}$ retinoic acid for $24 \mathrm{~h}$. The cells received ascorbic acid $2 \times$ /day during the incubation period. Comparable amounts of total RNA from control (lane 1 ) or retinoic acidtreated (lane 2) cells were subjected to

Northern blotting and then exposed to a ${ }^{32} \mathrm{P}$-labeled cDNA for the rat alpha 1 (1) collagen gene. The blot was then stripped and subsequently rehybridized with an $18 \mathrm{~s}$ ribosomal probe to assess the relative amounts of RNA loaded per lane. Arrows indicate the position of the 28s and 18s ribosomal RNA. The RNA was obtained by initially pooling the RNA from four $75-\mathrm{cm}^{2}$ flasks for control or retinoic acid-treated cells. The data was representative of 5 separate experiments each involving three to four $75-\mathrm{cm}^{2}$ flasks/condition. 


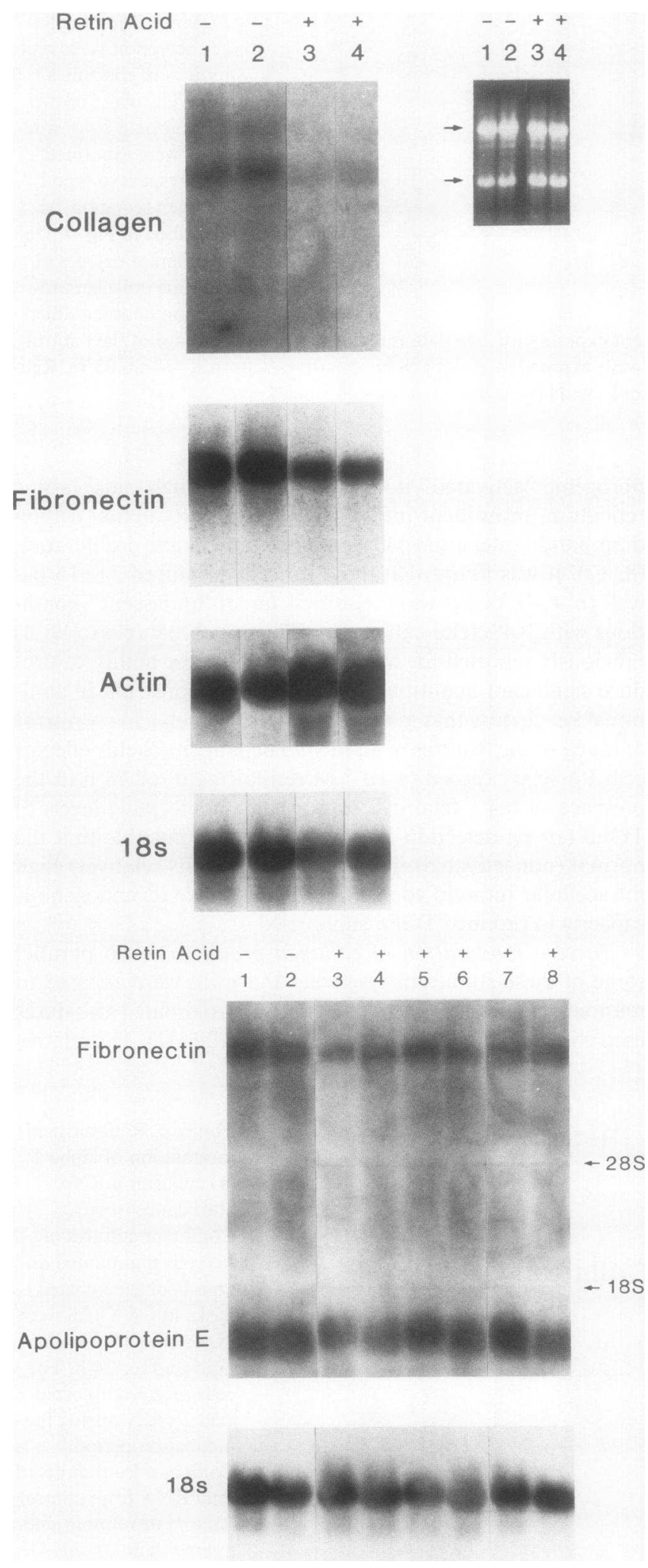

Figure 7. Retinoic acid modulation in vivo. $(A)$ Total hepatic mouse RNA or $(B)$ rat RNA was extracted from animals treated with retinoic acid or olive oil vehicle alone (as indicated) and then Northern blotted and exposed to a ${ }^{32} \mathrm{P}$-labeled cDNA for the rat alpha 1 (1) collagen gene. The same blots were then sequentially stripped and separately rehybridized with cDNAs for fibronectin, apolipoprotein $\mathrm{E}$, actin, and an $18 \mathrm{~s}$ ribosomal probe as indicated. There was no detectable rat collagen transcript despite prolonged $(5 \mathrm{~d})$ exposures
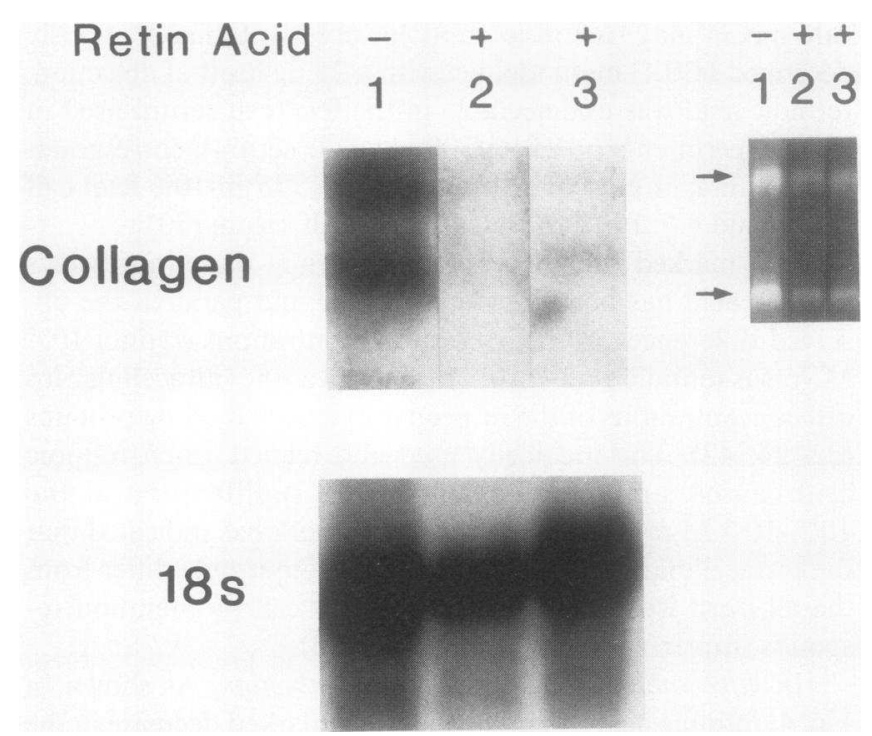

Figure 8. Retinoic acid modulation of Ito cell mRNA in vivo. Freshly isolated Ito cell RNA was extracted from animals treated with retinoic acid or olive oil vehicle alone (as indicated) and then Northern blotted and exposed to a ${ }^{32} \mathrm{P}$-labeled cDNA for the rat alpha 1 (1) collagen gene. The same blot was then sequentially stripped and separately rehybridized with cDNAs for fibronectin, apolipoprotein E, and an $18 \mathrm{~s}$ ribosomal probe. Despite a prolonged 5 d exposure, there was no detectable transcript for fibronectin or apolipoprotein $\mathrm{E}$ (data not shown). The comparable ethidium bromide stained gel is shown on the right. Arrows indicate the position of the 28s and 18 s ribosomal RNA. Each lane represents a separate animal. Comparable collagen transcript abundance was observed in 3 other Northern blots involving fresh Ito cell isolates from other untreated rats.

abundance of type I collagen mRNA was determined in whole liver RNA and in purified fresh rat Ito cell RNA and compared wtih that for fibronectin and apolipoprotein E mRNAs. Equivalence of RNA transfer was independently confirmed by reprobing the same Northern blots with an $18 \mathrm{~s}$ ribosomal probe. As shown in Fig. $7 \mathrm{~A}$, retinoic acid-treated mice had a significant reduction in the relative abundance of total hepatic type I collagen mRNA. The relative abundance of the actin transcript is shown for comparison. By contrast, type I collagen mRNA was undetectable in samples of total hepatic RNA from either retinoic acid-treated or control rats despite prolonged autoradiograph exposures (similar analysis of total RNA from fibrotic rat livers demonstrated the expected collagen transcript size data not shown). However, using RNA from isolated rat Ito cells, type I collagen mRNA was readily detectable in untreated rats, while retinoic acid treatment resulted in a reduction to undetectable levels (Fig. 8). There was no detectable fibronectin or apolipoprotein $\mathrm{E}$ transcript in the purified Ito cell Northern blots even after prolonged autoradiograph exposure. In contrast to the consistent alterations in collagen transcript abundance produced by retinoic acid administration in both mice and rats, a qualitative assessment of

(data not shown). A photograph of the comparable ethidium bromide stained gel for the mouse RNA is shown on the right. Arrows indicate the position of the $28 \mathrm{~s}$ and $18 \mathrm{~s}$ ribosomal RNA. Each lane represents a separate animal. 
the abundance of the fibronectin transcript in mice suggested a small ( $<40 \%$ after normalization to $18 \mathrm{~s}$ RNA abundance) diminution secondary to retinoic acid, but this modulation was not seen after examining a large number of similarly treated rats (Fig. $7 A$ and $B$ ). There was also no change in the relative abundance of the apolipoprotein $E$ transcript in the rats (Fig. 7 B) treated with retinoic acid.

\section{Discussion}

This study demonstrates that retinoic acid modulates Ito cell proliferation and collagen and TGF $\beta$ production in vitro and in vivo. This work suggests that retinoic acid should prove to be a useful tool in future in vitro or in vivo studies designed to consider the molecular factors that are altered during the pathologic fibrogenic state. Additional work would also clearly be needed to explore how retinoic acid modulates intracellular processes to prevent cell proliferation. Since previous studies involving retinol metabolism and the identical Ito cell culture system described herein have demonstrated that $\left[{ }^{3} \mathrm{H}\right]$ retinol is internalized by the cell, esterified to the predominant physiologic form, retinol palmitate, and is then capable of subsequent retinol ester hydrolysis, we speculate that retinoic acid, used in the current experiments, was effectively internalized by the Ito cells (21). This speculation is further supported by other work with Ito cells and retinoic acid in which microscopic lipid droplet formation was detected (a presumed storage form) after incubation of Ito cells in serum-containing media supplemented with retinoic acid (45). Similar analogies between retinol and retinoic acid metabolism are further supported by recent molecular analyses involving a comparison of cellular retinol binding protein and cellular retinoic acid binding protein metabolism and the corresponding retinol and retinoic acid (39). This work involved the well studied retinoid responsive embryonal carcinoma cell line, and demonstrated parallel retinol and retinoic acid shuttling between the cytoplasm and the nucleus, requiring the specific participation of the corresponding retinoid binding protein (39). This study and other recent work involving retinoid receptor anti-sense oligodeoxynucleotide methodology and the observations that epidermal growth factor receptor, laminin, and transglutaminase gene expression are transcriptionally regulated by retinoic acid, all support the speculation that the current study's observed alterations of Ito cell behavior may be mediated by the intracellular (and intranuclear) effects of retinoic acid (27, 46-51). Furthermore, the work with the embryonal carcinoma cell line underscores the complex nature of the intracellular handling of retinoic acid and suggests that measurements of total intracellular retinoic acid concentrations would not explain alterations in cell behavior but instead, the precise shuttling of retinoic acid bound to cellular retinoic acid binding protein to the nucleus and its interactions with nuclear binding proteins are likely to be the determining factors (39). Due to the very low concentrations of intracellular and intranuclear retinoic acid, it is likely that further work in this specific area will be done primarily in cell lines where sufficient cell material ( $>10^{9}$ cells) is readily available. Previous studies of Ito cell proliferation involving freshly isolated Ito cells suggest that increased cell growth begins to occur only after several days in primary culture coincident with the loss of the cell's vitamin A stores (20). After this initial lag in proliferation, however, Ito cells continue to proliferate in passaged culture in the presence of $10 \%$ serum for $>6$ passages over a 3-4-mo period. These cells maintain their differentiated phenotype through at least passage No. 3, as evidenced by their capacity to store vitamin A as retinol ester and hydrolyze retinol ester (21). As previously stated, the passaged cells maintain their biological responsiveness to retinol, the main circulating form of vitamin $A(8,19$, 20). This work demonstrates that retinoic acid inhibits cell proliferation and collagen production at $\geq 100 \times$ lower molar concentrations than used in previous studies with retinol (19, 20). This difference in sensitivity to retinol versus retinoic acid has been previously noted in other cell systems and may be especially important in any potential applications in vivo (24, 42). In other cell systems, however, the response to retinoic acid may differ considerably. For example, some work suggests that retinoic acid actually augments cell growth (24). Previous in vitro work with 10 -fold higher concentrations of retinoic acid had found, similar to Ito cells, that collagen over production by human keloid skin fibroblast cultures was inhibited, but the effect appeared to be at a pretranslational level (42).

This study found that TGF $\beta$ production was markedly reduced by retinoic acid, analogous to the reduction in collagen protein. A similar preliminary study found that 10 -fold higher concentrations of retinol depressed Ito cell TGF $\beta$ mRNA abundance by $>90 \%$ (10). Accumulating evidence suggests that collagen production may be causally linked to TGF $\beta$ in many cell systems $(4,52)$. It is possible then, that one of the mechanism(s) of retinoid modulation of collagen production relates to its effect on TGF $\beta$ accumulation. Future work, however, is needed to explore this potential causal link. These studies were extended to an initial characterization of the effects of retinoic acid administration in vivo to normal animals. By avoiding the use of animals with hepatic fibrosis or cirrhosis, the effect of retinoic acid on hepatic collagen gene expression was thereby assessed in the apparent absence of inflammatory or fibrogenic cytokines. In vivo administration of retinoic acid markedly reduced total hepatic and Ito cell type I collagen mRNA abundance, but was without significant effect upon rat hepatic fibronectin or apolipoprotein $E$ mRNA abundance. An unexpected finding in this study was encountered in our analysis of total hepatic RNA from rats where no detectable transcript for type I collagen could be demonstrated. While this may partly reflect the relative sensitivity of the hybridization method, it also suggests a very low transcript abundance in normal rat liver. Nevertheless, it bears emphasis that RNA isolated from purified Ito cells recovered from these same animals revealed abundant type I collagen mRNA and that, additionally, appeared responsive to administration of retinoic acid. These findings may relate to $(a)$ the use of different aged animals (rats, 9- vs. mice, 2-mo-old) or (b) differences in the relative total hepatic or Ito cell vitamin A content (53, 54). Recent work comparing 6- vs. 36-mo-old rats suggested that the vitamin A content of the Ito cells significantly increased without an apparent change in Ito cell number $(\sim 6 \%$ of total liver cells) $(22,53,54)$. Future studies are needed to resolve these apparent species or age related differences.

The factors that potentially modulate these key hepatic proteins in vivo are unknown, but one study has suggested that retinoic acid administration can diminish fibronectin mRNA abundance when animals have profound vitamin A deficiency (55). It is difficult, however, to extrapolate this finding to the current work that involved animals with normal vitamin $A$ containing diets. Recent work with vitamin A replete rats 
found that retinoic acid can increase hepatic transglutaminase levels within $12 \mathrm{~h}$ of administration, an effect that appeared to be exerted at a pretranslational level (46-48). This suggests that retinoic acid can stimulate as well as inhibit hepatic protein production. Another recent study using human skin fibroblast cultures to analyze collagen and fibronectin gene expression found a differential effect of gamma-interferon resulting in a decrease in collagen mRNA abundance but a marked increase in the mRNA for fibronectin (56). Data from these types of experiments are also difficult to apply to the in vivo setting where the cellular source of the two proteins may be different. Though in vitro work suggests that "activated" Ito cells may have the capacity of producing fibronectin, most studies suggest that in normal liver, the hepatocyte and the Kupffer cell are the likely sources of fibronectin $(55,57,58)$. Similarly, the hepatic source of apolipoprotein $\mathrm{E}$ is felt to be the hepatocyte and the Kupffer cell $(59,60)$. This work could not detect any fibronectin or apolipoprotein E mRNA in the purified fresh Ito cell mRNA despite their marked abundance in total liver mRNA. This supports the contention that the normal Ito cell is probably not a significant source of either of these proteins. The source of hepatic interstitial collagen in contrast appears to be the Ito cell and/or the hepatocyte, though each cell's relative contribution to total hepatic collagen remains somewhat controversial $(6,61-63)$. Therefore, the current study's finding of in vivo differential modulation of hepatic collagen versus rat fibronectin and apolipoprotein $\mathrm{E}$ mRNA abundance may be due to differences in retinoid responsive elements (i.e., nuclear binding proteins) present in Ito cells versus hepatocytes and Kupffer cells and/or differences in the factors that regulate the relative abundance of the three mRNA's.

While the molecular mechanism(s) of retinoic acid action appear to be at a nuclear level involving specific nuclear binding proteins, it is still unknown what determines this ubiquitous regulator's relative specificity (25-27). In the complex in vivo setting, it is possible that much of the retinoic acid selectively accumulates in the liver and perhaps in the Ito cell fraction. A retinoic acid metabolite may also be involved in the observed effect (64). The accumulated data involving the physiologic retinoid, retinol, at least strongly suggests that the hepatocyte and its adjacent Ito cell have developed an elaborate, incompletely understood mechanism of shuttling the retinoid predominantly to the Ito cell for both short- and long-term storage $(22,23)$. It seems unlikely that the retinoic acid effect was due to an increase in intracellular retinol because these animals were vitamin A sufficient, had abundant intracellular vitamin A stores, and most studies actually suggest that retinol may be converted to retinoic acid for the dominant mode of retinol action $(65,66)$. Future work will be needed to consider whether retinoic acid functions directly or indirectly by secondarily altering low levels of cytokine production (i.e., TGF $\beta$ ) or cytokine responsiveness (i.e., cytokine receptor expression, affinity, or more distal cytokine-induced effects). In this latter regard, we have recently observed that retinoic acid has the in vitro capacity of markedly reducing Ito cell cytokine responsiveness (67).

\section{Acknowledgments}

We wish to acknowledge the following for providing cDNA probes: Dr. Richard Hynes (fibronectin), Dr. Larry Kedes (actin), Dr. Ramareddy
Guntaka (18s ribosomal probe), Dr. John Taylor (apolipoprotein E), and Dr. David Rowe (rat alpha 1 (I) collagen). We also thank Dr. Joseph A. Madri (Yale University) for collagens and antibodies used in ELISAs, Dr. Roberts and Dr. Danielpour (National Institutes of Health) for generously providing TGF $\beta$ and TGF $\beta$ antiserum used in the ELISA, and Dr. Wesley E. Jensen (University of Chicago) for HPLC quantitation of retinoic acid.

This work was supported in part by National Institute of Health grants HL-38189 (to Dr. Davidson), DK-40223 (to Dr. Davis), Research Career Development Award K04 HL-02166, American Heart Association Grant-in-Aid 88-1015, and American Gastroenterology Association/Smith Kline and French Scholar Award (to Dr. Davidson), and American Gastroenterology Association/Hoffmann-La Roche Scholar Award and the Liver Research Fund, University of Chicago, Chicago, Illinois (to Dr. Davis).

\section{References}

1. Braun, L., J. E. Mead, M. Panzica, R. Mikumo, G. I. Bell, and N. Fausto. 1988. Transforming growth factor $\beta$ mRNA increases during liver regeneration: a possible paracrine mechanism of growth regulation. Proc. Natl. Acad. Sci. USA. 85:1539-1543.

2. Czaja, M. J., F. R. Weiner, K. C. Flanders, M. Giambrone, R. Wind, L. Biempica, and M. A. Zern. 1989. In vitro and in vivo association of transforming growth factor- $\beta 1$ with hepatic fibrosis. J. Cell Biol. 108:2477-2482.

3. Mead, J. E., and N. Fausto. 1989. Transforming growth factor alpha may be a physiological regulator of liver regeneration by means of an autocrine mechanism. Proc. Natl. Acad. Sci. USA. 86:15581562.

4. Sporn, M. B., and A. B. Roberts. 1988. Peptide growth factors are multifunctional. Nature (Lond.). 332:217-219.

5. Danielpour, D., L. L. Dart, K. C. Flanders, A. B. Roberts, and M. B. Sporn. 1989. Immunodetection and quantitation of the two forms of transforming growth factor-beta (TGF $\beta 1$ and TGF $\beta 2$ ) secreted by cells in culture. J. Cell. Physiol. 138:79-86.

6. Friedman, S. L., F. J. Roll, J. Boyles, and D. M. Bissell. 1985. Hepatic lipocytes: the principal collagen-producing cells of normal rat liver. Proc. Natl. Acad. Sci. USA. 82:8681-8685.

7. Senoo, H., R. Hata, Y. Nagai, and K. Wake. 1984. Stellate cells (vitamin A-storing cells) are the primary site of collagen synthesis in non-parenchymal cells in the liver. Biomed. Res. 5:451-458.

8. Davis, B. H., B. M. Pratt, and J. A. Madri. 1987. Retinol and extracellular collagen matrices modulate hepatic Ito cell collagen phenotype and cellular retinol binding protein levels. J. Biol. Chem. 262:10280-10286.

9. Geerts, A., R. Vrijsen, P. Schellinck, and E. Wisse. 1989. Retinol affects the phenotype and protein synthesis of fat-storing cell derived myofibroblasts in vitro. In Cells of the Hepatic Sinusoid. E. Wisse, D. L. Knook, and K. Decker, editors. Kupffer Cell Foundation, Rijswijk, The Netherlands. 20-24.

10. Shah, A., and F. R. Weiner. 1989. Effects of retinoids on collagen and transforming growth factor- $\beta 1$ (TGF- $\beta 1$ ) gene expression in Ito cells. Hepatology (Baltimore). 10:630 (Abstr.).

11. Ballardini, G., S. D. Esposti, F. B. Bianchi, L. B. De Giorgi, A. Faccani, L. Biolchini, C. A. Busachi, and E. Pisi. 1983. Correlation between Ito cells and fibrogenesis in an experimental model of hepatic fibrosis. A sequential stereological study. Liver. 3:58-63.

12. Kent, G., S. Gay, T. Inouye, R. Bahu, O. T. Minick, and H. Popper. 1976. Vitamin A-containing lipocytes and formation of type III collagen in liver injury. Proc. Natl. Acad. Sci. USA. 73:3719-3722.

13. Mak, K. M., M. A. Leo, and C. S. Lieber. 1984. Alcoholic liver injury in baboons: transformation of lipocytes to transitional cells. Gastroenterology. 87:188-200.

14. Minato, Y., Y. Hasumura, and J. Takeuchi. 1983. The role of fat-storing cells in Disse space fibrogenesis in alcoholic liver disease. Hepatology. 3:559-566. 
15. Friedman, S. L., and M. J. P. Arthur. 1989. Kupffer cell mediated proliferation of lipocytes occurs via induction of receptors for platelet-derived growth factor-studies in rats and humans. Hepatology. 10:632.

16. Friedman, S. L., and W. S. Blaner. 1989. Activation of cultured lipocytes by Kupffer cell medium (KCM) is accompanied by release of retinol. Gastroenterology. 96:A598.

17. Geerts, A., R. Vrijsen, J. Rauterberg, A. Burt, P. Schellinck, and E. Wisse. 1989. In vitro differentiation of fat-storing cells parallels marked increase of collagen synthesis and secretion. J. Hepatology. 9:59-68.

18. Shiratori, Y., T. Ichida, A. Geerts, and E. Wisse. 1987. Modulation of collagen synthesis by fat-storing cells, isolated from $\mathrm{CCl}_{4}$ or vitamin A-treated rats. Dig. Dis. Sci. 32:1281-1289.

19. Davis, B. H. 1988. Transforming growth factor $\beta$ responsiveness is modulated by the extracellular collagen matrix during hepatic Ito cell culture. J. Cell. Physiol. 136:547-53.

20. Davis, B. H., and A. Vucic. 1988. The effect of retinol on Ito cell proliferation in vitro. Hepatology. 8:788-793.

21. Davis, B. H., and A. Vucic. 1989. Modulation of vitamin A metabolism during hepatic and intestinal cell culture. Biochim. Biophys. Acta. 1010:318-324.

22. Blomhoff, R., M. Rasmussen, A. Nilsson, K. R. Norum, T. Berg, W. S. Blaner, M. Kato, J. R. Mertz, D. S. Goodman, U. Eriksson, and P. A. Peterson. 1985. Hepatic retinol metabolism: distribution of retinoids, enzymes, and binding proteins in isolated rat liver cells. $J$. Biol. Chem. 260:13560-13565.

23. Blomhoff, R., K. R. Norum, and T. Berg. 1985. Hepatic uptake of $\left[{ }^{3} \mathrm{H}\right]$ Retinol bound to the serum retinol binding protein involves both parenchymal and perisinusoidal stellate cells. J. Biol. Chem. 260:13571-13575.

24. Roberts, A. B., and M. B. Sporn. 1984. Cellular biology and biochemistry of the retinoids. In The Retinoids. M. Sporn, A. B. Roberts, and D. S. Goodman, editors. Academic Press Inc., Orlando, FL 2:210-276.

25. Giguere, V., E. S. Ong, P. Segui, and R. M. Evans. 1987. Identification of a receptor for the morphogen retinoic acid. Nature (Lond.). 330:624-629.

26. Benbrook, D., E. Lernhardt, and M. Pfahl. 1988. A new retinoic acid receptor identified from a hepatocellular carcinoma. Nature (Lond.). 333:669-672.

27. Cope, F. O., and J. J. Wille. 1989. Retinoid receptor antisense DNAs inhibit alkaline phosphatase induction and clonogenicity in malignant keratinocytes. Proc. Natl. Acad. Sci. USA. 86:5590-5594.

28. McGowan, J. A., A. J. Strain, and N. L. R. Bucher. 1981. DNA synthesis in primary cultures of adult rat hepatocytes in a defined medium: effects of epidermal growth factor, insulin, glucagon, and cyclic-AMP. J. Cell. Physiol. 108:353-363.

29. Kraemer, K. H., J. J. DiGiovanna, A. N. Moshell, R. E. Tarone, and G. L. Peck. 1988. Prevention of skin cancer in xeroderma pigmentosum with the use of oral isotretinoin. N. Engl. J. Med. 318:1633-1637.

30. Madhok, R., S. A. Muller, and C. H. Dicken. 1987. Treatment of psoriasis with etretin: a preliminary report. Mayo Clin. Proc. 62:1084-1089.

31. Goldfarb, M. T., C. N. Ellis, and J. J. Voorhees. 1987. Retinoids in dermatology. Mayo Clin. Proc. 62:1161-1164.

32. Chomczynski, P., and N. Sacchi. 1987. Single step method of RNA isolation by acid guanidinium thiocyanate-phenol-chloroform extraction. Anal. Biochem. 162:156-159.

33. Feinberg, A. P., and B. Vogelstein. 1983. A technique for radiolabeling DNA restriction endonuclease fragments to high specific activity. Anal. Biochem. 132:6-13.

34. Gunning, P., P. Ponte, H. Okayama, J. Engel, H. Blau, and L. Kedes. 1983. Isolation and characterization of full-length cDNA clones for human alpha, beta, and gamma-actin mRNAs: skeletal but not cytoplasmic actins have an amino-terminal cysteine that is subsequently removed. Mol. Cell. Biol. 3:787-795.
35. Schwartzbauer, J. E., J. W. Tamkun, I. R. Lemischka, and R. O. Hynes. 1983. Three different fibronectin mRNAs arise by alternative splicing within the coding region. Cell. 35:421-431.

36. Genovese, C., D. Rowe, and B. Kream. 1984. Construction of DNA sequences complementary to rat alpha 1 and alpha 2 collagen mRNA and their use in studying the regulation of type I collagen synthesis by 1,25-dihydroxyvitamin D. Biochemistry. 23:6210-6216.

37. Katz, R. A., B. F. Erlanger, and R. V. Guntaka. 1983. Evidence for extensive methylation of ribosomal DNA genes in a rat xc cell line. Biochim. Biophys. Acta. 739:258-264.

38. Mclean, J. W., C. Fukazawa, and John M. Taylor. 1983. Ra apolipoprotein E mRNA-cloning and sequencing of double-started cDNA. J. Biol. Chem. 235:8993-9000.

39. Barkai, U. and Sherman, M. I. 1987. Analyses of the interactions between retinoid-binding proteins and embryona carcinoma cells. J. Cell Biol. 104:671-678.

40. Wakefield, L. M., Smith, D. M., Flanders, K. C., and M. B. Sporn. 1988. Latent transforming growth factor- $\beta$ from human platelets: a high molecular weight complex containing precursor sequences. J. Biol. Chem. 263:7646-7654.

41. Tang, G., and R. M. Russell. 1988. Beta-carotene and retinol palmitate supplements can increase retinoic acid levels in human blood. J. Am. Coll. Nutr. 7:399.

42. Oikarinen, H., A. I. Oikarinen, E. M. L. Tan, R. P. Abergel, C. A. Meeker, M. L. Chu, D. J. Prockop, and J. Uitto. 1985. Modulation of procollagen gene expression by retinoids inhibition of collagen production by retinoic acid accompanied by reduced type I procollagen messenger ribonucleic acid levels in human skin fibroblast cultures. J. Clin. Invest. 75:1545-1553.

43. Ball, M. D., and J. A. Olson. 1988. 13-cis-Retinoic acid stimulates in vitro mannose 6-phosphate hydrolysis and inhibits retinol esterification and benzo(a)pyrene hydroxylation by rat-liver microsomes. Biochim. Biophys. Acta. 961:139-143.

44. Assoian, R. K., B. E. Fleurdelys, H. C. Stevenson, P. J. Miller, D. K. Madtes, E. W. Raines, R. Ross, and M. B. Sporn. 1987. Expression and secretion of type $\beta$ transforming growth factor by activated human macrophages. Proc. Natl. Acad. Sci. USA. 84:6020-6024.

45. Chen, W., J.-L. Gendrault, A.-M. Steffan, E. Jeandidier, and A. Kirn. 1989. Isolation, culture and main characteristics of mouse fatstoring cells: interaction with viruses. Hepatology. 9:352-362.

46. Thompson, K. L., and M. R. Rosner. 1989. Regulation of epidermal growth factor receptor gene expression by retinoic acid and epidermal growth factor. J. Biol. Chem. 264:3230-3234.

47. Murtaugh, M. P., O. Dennison, J. P. Stein, and P. J. A. Davies. 1986. Retinoic acid-induced gene expression in normal and leukemic myeloid cells. J. Exp. Med. 163:1325-1330.

48. Piacentini, M., L. Fesus, C. Sartori, and M. P. Ceru. 1988. Retinoic acid-induced modulation of rat liver transglutaminase and total polyamines in vivo. Biochem. J. 253:33-38.

49. Chiocca, E. A., P. J. A. Davies, and J. P. Stein. 1988. The molecular basis of retinoic acid action: transcriptional regulation of tissue transglutaminase gene expression in macrophages. J. Biol. Chem. 263:11584-11589.

50. Nara, K., K. Nakanishi, H. Hagiwara, K. Wakita, S. Kojima, and S. Hirose. 1989. Retinol-induced morphological changes of cultured bovine endothelial cells are accompanied by a marked increase in transglutaminase. J. Biol. Chem. 264:19308-19312.

51. Vasios, G. W., J. D. Gold, M. Petkovich, P. Chambon, and L. J. Gudas. 1989. A retinoic acid-responsive element is present in the 5 flanking region of the laminin B1 gene. Proc. Natl. Acad. Sci. USA. 86:9099-9103.

52. Schilling, E. V. O., N. S. Roche, K. C. Flanders, M. B. Sporn, and A. B. Roberts. 1988. Transforming growth factor $\beta 1$ positively regulates its own expression in normal and transformed cells. J. Biol. Chem. 263:7741-7746.

53. Hendriks, H. F. J., W. S. Blaner, H. M. Wennekers, R. Piantedosi, A. Brouwer, A. M. de Leeuw, D. S. Goodman, and D. L. Knook. 1988. Distributions of retinoids, retinoid-binding proteins and related 
parameters in different types of liver cells isolated from young and old rats. Eur. J. Biochem. 171:237-244.

54. Hendriks, H. F. J., W. S. Blaner, H. M. Weenekers, A. Brouwer, A. M. De Leeuw, D. S. Goodman, and D. L. Knook. 1986. Distribution of retinoids, some retinoid binding proteins and retinyl palmitate hydrolase activity in different liver cell types isolated from young and old rats. In Cells of the Hepatic Sinusoid. A. Kirn, D. L. Knook, and E. Wisse, editors. Kupffer Cell Foundation, Rijswijk, The Netherlands. 201-202.

55. Kim, H. Y., and G. Wolf. 1987. Vitamin A deficiency alters genomic expression for fibronectin in liver and hepatocytes. J. Biol. Chem. 262:365-371.

56. Czaja, M. J., F. R. Weiner, M. Eghbali, M. Giambrone, M. Eghbali, and M. A. Zern. 1987. Differential effects of gamma-interferon on collagen and fibronectin gene expression. J. Biol. Chem. 262:13348-13351.

57. Vincent, P. A., E. Cho, and T. M. Saba. 1989. Effect of repetitive low-dose endotoxin on liver parenchymal and Kupffer cell fibronectin release. Hepatology. 9:562-569.

58. Ramadori, G., H. Rieder, Th. Knittel, H. P. Dienes, and M. Buschenfelde. 1987. Fat-storing cells (FSC) of rat liver synthesize and secret fibronectin, comparison with hepatocytes. J. Hepatol. (Amst.) 41:190-197.

59. Dawson, P. A., Lukaszewski, L. M., Ells, P. F., Malbon, C. C., and Williams, D. L. 1989. Quantification and regulation of apolipoprotein E expression in rat Kupffer cells. J. Lipid Res. 30:430-413.
60. Reue, K. L., D. H. Quon, K. A. O'Donnell, G. J. Dizikes, G. C. Fareed, and A. J. Lusis. 1984. Cloning and regulation of messenger RNA for mouse apolipoprotein E. J. Biol. Chem. 259:2100-2107.

61. Clement, B., J. A. Grimaud, J. P. Campion, Y. Deugnier, and A. Guillouzo. 1986. Cell types involved in collagen and fibronectin production in normal and fibrotic human liver. Hepatology. 6:225234.

62. Chojkier, M. 1986. Hepatocyte collagen production in vivo in normal rats. J. Clin. Invest. 78:333-339.

63. Maher, J. J., D. M. Bissell, S. L. Friedman, and F. J. Roll. 1988. Collagen measured in primary cultures of normal rat hepatocytes derives from lipocytes within the monolayer. J. Clin. Invest. 82:450-459.

64. Deluca, H. F., M. Zile, and W. K. Sietsema. 1981. The metabolism of retinoic acid to 5,6-epoxyretinoic acid, retinoyl- $\beta$-glucuronide, and other polar metabolites. Ann. NY Acad. Sci. 359:25-36.

65. Bhat, P. V., and A. M. Jetten. 1987. Metabolism of all-trans-retinol and all-trans-retinoic acid in rabbit tracheal epithelial cells in culture. Biochim. Biophys. Acta. 922:18-27.

66. Napoli, J. L., and K. R. Race. 1987. The biosynthesis of retinoic acid from retinol by rat tissues in vitro. Arch. Biochem. Biophys. 255:95-101.

67. Davis, B. H., and C. Moran. 1989. Regulation of hepatic platelet-derived growth factor receptor expression. Hepatology. 10:621 (Abstr.) 